\title{
Mudanças em sistemas estaduais de ensino em face das reformas no Ensino Médio e no Ensino Técnico*
}

Celso João Ferretti **

\begin{abstract}
RESUMO: Esta é uma análise da nova proposta governamental para a estrutura de ensino do Ensino Médio para a educação profissional, apontando para as diferenças entre a técnica e a instrução tecnológica no âmbito do discurso oficial e da introdução prática da proposta. Usando dados empíricos de escolas técnicas após tais mudanças, o texto argumenta as propriedades das práticas escolares para o ensino tecnológico, mostrando a perda da identidade desse tipo de escola, dando uma resposta ao ensino tecnológico engajado com a educação social.
\end{abstract}

Palavras-chave: Ensino Médio, políticas públicas, ensino tecnológico, identidade

O presente artigo tem por objeto o exame de propostas de reestruturação do antigo Ensino Técnico que vêm sendo feitas, desde 1996, visando conformá-lo à nova legislação educacional, em particular à LDB (Lei 9394/96) e ao Decreto-Lei 2208/97.

Tais propostas originaram-se em três sistemas estaduais de ensino - o do Paraná, o de Minas Gerais e o de São Paulo -, evidenciando os esforços dos respectivos governos no sentido de promover alterações nesse nível de ensino, mesmo quando a legislação acima referida ainda não tinha sido homologada (caso específico do Paraná e de Minas Gerais). Tal procedimento reforça a leitura, feita por vários educadores

\footnotetext{
* Este artigo baseou-se em partes do livro Diagnóstico da formação profissional. Ramo metalúrgico, publicado pela CNM/CUT e pela Unitrabalho em 1999, elaborado por uma equipe nacional de pesquisadores da qual o autor participou.

** Professor do Programa de Estudos Pós-graduados em Educação: História, Política, Sociedade, da PUC-SP e pesquisador da Fundação Carlos Chagas. Email:cferretti@cc.org.br
} 
brasileiros, de que, em relação a determinadas facetas, mais do que a LDB, o que tem de fato estruturado o ensino brasileiro no período recente são medidas tomadas no plano do poder executivo, segundo definições traçadas antes mesmo de que a legislação maior do ensino obtivesse aprovação. O Decreto-Lei 2208/97, cujo conteúdo, na sua essência, não difere do Projeto de Lei 1603/96, é um bom exemplo desse procedimento.

No entanto, antes de tratar das propostas recentes de reformulação do Ensino Técnico nos três estados referidos, deve-se fazer uma consideração de ordem geral que se refere não apenas a esses, mas a todos os sistemas estaduais de ensino brasileiros, no que tange ao Ensino Médio e ao Ensino Técnico. Como se sabe, antes da Lei $9394 / 96$ e do Decreto 2208/97, os então chamados cursos de $2^{\circ}$ grau, quer na modalidade de cursos profissionalizantes, quer na forma de cursos técnicos (ainda na perspectiva da profissionalização compulsória regida pela Lei 5692/71 e pelos Pareceres 45/72 e 76/ 75 ), ofereciam, na mesma escola e com algum nível de integração (conforme sugerem as respostas oferecidas por vários cursos investigados), formação geral (sob a denominação de núcleo comum do currículo) e formação técnica (sob a denominação de disciplinas específicas). Várias escolas, de diferentes sistemas estaduais de ensino, já não ofereciam mais cursos profissionalizantes nos anos recentes, com apoio na Lei 7044/82. Tal lei representou, na prática, para as escolas estaduais de $2^{\circ}$ grau, o reconhecimento legal do fracasso da profissionalização compulsória, ao mesmo tempo que as liberava para oferecer, às claras, a formação propedêutica que boa parte delas nunca havia deixado de manter, na forma dos mais variados disfarces curriculares. No entanto, essa legislação não afetava o Ensino Técnico na sua estrutura curricular, devendo este continuar a promover formação que contemplasse tanto o núcleo comum quanto as disciplinas específicas, situação que se altera, como já se viu, com a nova legislação.

\section{Osistema estadual de ensino do Paraná e a reforma}

O primeiro caso a ser analisado é o do Paraná, pelo papel paradigmático que desempenhou na gestão Jaime Lerner (1994-1997), de verdadeiro laboratório para criação e experimentação de alternativas para o Ensino Técnico, com base nas perspectivas delineadas por agências internacionais (cf. Ferretti 1997).

Antecipando-se às políticas nacionais para educação profissional de nível técnico, o governo estadual, por intermédio da Secretaria do Estado de Educação, desenvolveu estudos, desde o início da gestão, 
que culminaram na elaboração do Programa Expansão, Melhoria e Inovação no Ensino Médio do Paraná (Proem). Com esse programa, a partir de 1996, as matrículas para o antigo ensino profissionalizante de $2^{\circ}$ grau deixaram de ser abertas pela maioria das escolas; algumas poucas exceções se deveram a pressões de sindicatos, partidos, do Fórum Estadual em Defesa da Escola Pública, paralelamente a outros setores organizados da sociedade civil que conseguiram, com sua mobilização, obter do governo a permissão para que as decisões a respeito fossem tomadas pelos Conselhos Escolares. Como essa possibilidade deu-se quando muitas escolas já haviam cumprido a determinação do governo, a eficácia da medida foi restrita e logo suplantada pela determinação, por meio do Proem, da não oferta de vagas para o antigo ensino profissionalizante por todo o sistema estadual, a partir de 1997.

Para sua concepção e sua implementação o Proem recebeu apoio financeiro do BID, tendo sido considerado, na época, modelo para a América Latina, por estar de acordo com as políticas formuladas para o ensino, pelos agentes financeiros internacionais, nos países em desenvolvimento. Tais recursos foram da ordem de $R \$ 100$ milhões, a serem complementados pela contrapartida do governo estadual da ordem de $\mathrm{R} \$ 122$ milhões, no prazo de cinco anos.

A discussão sobre o Proem deve ser feita sob duas perspectivas. A primeira diz respeito à forma pela qual interfere na estrutura do ensino de nível técnico. Resumidamente, a proposta consiste em separar a educação geral da formação profissional, o que coincide com as propostas do banco, adotadas pelo governo federal no Decreto 2208/97, cuja aprovação, aliás, constituiu condição imposta pelo BID para liberação de recursos da ordem de $R \$ 500$ milhões, tendo em vista a reformulação do Ensino Técnico.

De acordo com o Proem, o Ensino Médio passaria a ser ofertado apenas na modalidade de educação geral, enquanto o ensino profissional seria desenvolvido como modalidade específica, separadamente daquela. Os estabelecimentos de ensino que ofereciam habilitações profissionais deixariam de fazê-lo, devendo ter seus espaços e projetos pedagógicos reformulados para ofertar Ensino Médio de educação geral. Por seu turno, as instituições que tinham tradição de Ensino Técnico passariam pelas mesmas reformulações, transformando-se em centros de educação técnica, distribuídos pelo estado em atenção às peculiaridades regionais. Segundo a proposta, a localização dos centros deveria ser decidida com base em debates com as comunidades locais e em estudos socioeconômicos que evidenciassem a vocação regional e a empregabilidade. De acordo com o documento oficial, o fa- 
tor decisivo na definição do “(...) número de vagas a ser ofertado (seria) a empregabilidade. O objetivo (seria o de) não cometer os erros (existentes) da oferta de ensino profissionalizante, sem levar em conta a demanda estabelecida pelo setor produtivo" (Seed/PR 1995, p. 5).

Tome-se como exemplo a área do Ensino Técnico Industrial. Para esta o Proem previa a instalação de seis centros: em Curitiba (IPE), Cascavel (Colégio Polivalente), Londrina, Ponta Grossa, Maringá e Guarapuava, por serem tais cidades consideradas pólos de desenvolvimento industrial. As ofertas de alguns cursos deveriam ser comuns a esses centros (por exemplo, o de mecatrônica). Os cursos deveriam ter uma duração de seis meses a dois anos, dependendo da complexidade de cada um, podendo ser criados, dependendo da necessidade, em escolas que ofertassem cursos médios de educação geral.

As vagas seriam oferecidas de acordo com a demanda do mercado de trabalho, o que, ao contrário do que reza o discurso oficial, revestiria esses cursos de caráter duplamente elitista; primeiro, porque é muito reduzido o número de jovens que concluem o Ensino Médio, e, dentre estes, a maioria destina-se ao Ensino Superior; segundo, porque as ofertas de emprego ou de ocupações no setor formal tendem a diminuir cada vez mais, particularmente no setor industrial, dadas as características estruturais dessa etapa de desenvolvimento das forças produtivas.

Essa constatação remete à segunda perspectiva de exame referente às conseqüências da reformulação proposta para a democratização do Ensino Técnico. Nesse particular verifica-se que a solução adotada para instituir as relações da educação geral com a formação profissional resultou no estabelecimento da ruptura definitiva entre ambas do ponto de vista da estrutura do sistema de ensino, uma vez que a proposta do Proem obedecia à seguinte racionalidade: para os que passassem pelo crivo da seletividade, um Ensino Médio acadêmico, vinculado ao trabalho de forma ampla, assegurando a formação indispensável para o exercício da cidadania e tendo em vista a continuidade dos estudos. Para os que não o conseguissem, o ensino profissional, integrando as diferentes formas de educação para o trabaIho, por meio do qual o jovem receberia alguma formação para inserir-se no mercado, diminuindo assim a pressão sobre o ensino público oferecido pelas universidades, com o que se cumpriria a função de represar a demanda.

Nesse sentido o Proem, com sua inflexibilidade, apenas legitimou a inclusão dos incluídos, ao mesmo tempo que buscou atender as demandas do mercado, contribuindo para a extinção das possibilidades múltiplas anteriormente existentes. Revelou-se, assim, uma opção perversa para os trabalhadores com menores oportunidades de acesso ao Ensino Médio. 
De acordo com a proposta, a administração do Proem seria realizada pela Paranatec, uma organização social (instituição privada sem fins lucrativos), criada por meio de parceria entre a Seed, Cefet-PR, o Senai, Senac, o Senar e o Sebrae, para coordenar as diversas ações na educação técnico-profissional no Paraná.

A criação de tais organizações sociais, estimulada pelo governo federal, tem sido bastante criticada, por se contrapor ao princípio da gestão pública dos recursos públicos. Organizadas como instituições privadas, possibilitam a utilização de recursos públicos sem os controles de Estado, a não obrigatoriedade de cumprimento da lei de licitações, a contratação com base na CLT, não garantindo os direitos dos trabalhadores em termos de estabilidade no emprego e plano de cargos e salários, configurando, enfim, a gestão privada de recursos públicos. Essa autonomia, no entanto, era vista pelo governo como bastante positiva, uma vez que poderia viabilizar maior produtividade por parte de instituições estruturadas em moldes empresariais.

\section{A relação entre demandas econômicas e a organização do Ensino Médio e do Ensino Técnico em Minas Gerais}

A Secretaria da Educação do Estado de Minas Gerais publicou, em 1996, um amplo estudo que abrangeu:

- a distribuição dos cursos profissionalizantes dos sistemas de ensino federal, estadual, municipal e particular no Estado (Minas Gerais, SEE, Doc. 1, 1996);

- a estimativa da população em idade escolar no Estado no período 1991-2006 (Minas Gerais, SEE, Doc. 2, 1996);

- a análise da adequação entre as características econômicas das superintendências regionais de ensino e oferta de cursos de $2^{\circ}$ grau, profissionalizante e não profissionalizante (Minas Gerais, SEE, Doc. 3, 1996).

O estudo visava o que está indicado no $3^{\circ}$ documento, ou seja, uma adequação dos cursos de $2^{\circ}$ grau, profissionalizantes e não profissionalizantes, às demandas econômicas regionais do estado, entrevendo - e, em certo sentido, incorporando - as perspectivas descortinadas, naquele momento, pela LDB em discussão e pelo Projeto de Lei 1603/96. Trata-se, portanto, de documentos que discutem, já em 1996, as possíveis mudanças que a rede estadual de ensino de $2^{\circ}$ grau, principalmente, deveria sofrer para 
promover a maior integração entre educação e produção. Os dados referentes aos cursos regulares foram obtidos no Catálogo dos Estabelecimentos de Ensino de $2^{\circ}$ Grau por Curso e Habilitação Profissional, editado pela Secretaria da Educação em 1995, ao passo que os relativos a Senai, Ultramig, Cefet e Senac foram obtidos nessas instituições. O estudo procurou ainda realizar levantamento da mesma natureza sobre os cursos livres, encontrando muita dificuldade pela ausência de cadastro (situação que pode ser generalizada para outros estados).

As informações relativas à economia do estado foram obtidas no "perfil socioeconômico das regiões de planejamento (...)" elaborado pela Secretaria de Planejamento/Seplan, assim como em documento elaborado pela FIEMG. ${ }^{1}$

O levantamento permitiu identificar 2894 cursos, dos quais $33,38 \%$ eram denominados "acadêmicos" (cursos médios que não oferecem habilitações profissionais), 30,54\% eram de formação de professores (antigo curso normal) e $20,18 \%$ eram de técnico em contabilidade. Os três tipos perfaziam $84,1 \%$ do total de cursos de $2^{\circ}$ grau levantados nas diferentes redes e instituições pesquisadas e os únicos presentes em todas as superintendências de ensino (SREs). A rede estadual de ensino era responsável por $69 \%$ dos cursos de contabilidade, por $77 \%$ dos cursos de habilitação ao magistério e por $63 \%$ dos cursos "acadêmicos". Além desses foram identificados vários outros cursos profissionalizantes distribuídos por diferentes áreas.

Para fins deste artigo far-se-á referência apenas àqueles relacionados ao setor metal-mecânico, incluídos no catálogo anteriormente mencionado, entre os cursos da área industrial. Dos 2894 cursos levantados, 167 (ou 5,8\% deles) faziam parte dessa categoria e, desse número, 38\% (ou 64 cursos) localizavam-se no Pólo Regional Metropolitano. ${ }^{2}$ Segundo o documento, "nessa área há uma maior participação do sistema particular, que mantém $47 \%$ dos cursos, vindo a seguir o sistema estadual, com $34 \%$ (...)" (SEE, Doc. 1, 1996, p. 10). Incluíam-se nos cursos dessa área que se relacionam ao setor metal-mecânico os de auxiliar técnico de eletrotécnica, auxiliar técnico de eletrônica, desenho mecânico, habilitação básica em mecânica, inspetor de segurança do trabalho, técnico em desenho industrial, técnico em eletromecânica, técnico em eletrônica, técnico em eletrotécnica, técnico em manutenção de aeronaves, técnico em mecânica, técnico em metalurgia, técnico em construção de navios e manobras de peso.

De acordo com as análises constantes do Doc. 1 da SEE, haveria correspondência entre a oferta de cursos da área industrial e as características econômicas do Pólo Metropolitano e do Pólo Norte. O mesmo não 
ocorreria em relação ao Pólo do Vale do Aço, ressaltando-se a necessidade de "maior desenvolvimento de cursos voltados para a principal atividade regional que é a siderurgia (...) (SEE, Doc. 1, 1996, p. 19). Da mesma forma, o documento ressaltava a necessidade de considerar as novas demandas que seriam criadas com a instalação de uma montadora de automóveis em Juiz de Fora (Pólo Mata), bem como para o desenvolvimento de indústrias de alta tecnologia no Pólo Regional Sul, incluindo o ramo de eletrônica e de metalurgia (especialmente autopeças).

Entre as sugestões de caráter geral apresentadas no documento estava a de "ampliar o número de cursos ligados às atividades de siderurgia, como cursos de metalurgia, por exemplo (...)" (SEE, Doc. 1, p. 22). Foram feitas, além disso, sugestões específicas para criação ou desenvolvimento de cursos voltados para o uso de novas tecnologias em regiões de maior concentração industrial ou que teriam potencial para tal (SREs de Conselheiro Lafaiete, de Coronel Fabriciano, de Juiz de Fora, de Montes Claros, de Nova Era, de São Sebastião do Paraíso e de Varginha), supondo-se que as indústrias locais se pautariam pelo uso de tais tecnologias e que, ao fazê-lo, abririam oportunidades de emprego aos egressos dos cursos profissionalizantes.

\section{A rede estadual de Ensino Técnico em São Paulo e as propostas de mudança perante as reformas}

Diferentemente do que ocorreu no Paraná e em Minas Gerais, as mudanças mais profundas no Ensino Técnico de São Paulo passaram a ocorrer após a publicação do Decreto 2208/97. No geral promoveu-se o bloqueio de matrículas nas séries iniciais dos cursos de $2^{\circ}$ grau profissionalizantes ainda existentes na rede estadual de ensino, ao mesmo tempo que se determinou a separação entre o Ensino Médio e o Ensino Técnico. Este vinha sendo oferecido em São Paulo pelo Centro Estadual de Educação Tecnológica Paula Souza (Ceeteps), instituição criada em 1976 e vinculada à Universidade Estadual Paulista "Júlio de Mesquita Filho" (Unesp), a qual goza, como autarquia, de autonomia administrativa, financeira, didática e disciplinar. No entanto, o Ceeteps, na sua origem, não era responsável por cursos técnicos de $2^{\circ}$ grau, estando sob sua jurisdição apenas as faculdades de tecnologia. Essa responsabilidade foi assumida gradativamente pela instituição, em face do descaso ou da dificuldade encontrada pela Secretaria da Educação do Estado para continuar administrando a rede de Ensino Técnico existente no estado após os su- 
cessivos percalços desencadeados pela vigência da Lei 5692/71. Assim, o Ceeteps assumiu, inicialmente, um grupo restrito de 18 escolas técnicas.

Nos anos 90, as restantes escolas da rede estadual de Ensino Técnico passaram a fazer parte do quadro da Secretaria Estadual de Ciência e Tecnologia, acompanhando medida que também estava sendo adotada pelo estado do Rio de Janeiro, sugerindo, portanto, a existência de uma política mais ampla em relação à responsabilidade pela gestão desse tipo de instituição. Desde essa época a supervisão e o gerenciamento das 99 escolas técnicas estaduais então existentes passaram a ser realizados pelo Ceeteps, todas elas funcionando de acordo com as determinações da LDB então vigente, conforme depoimento de membro da direção da instituição:

Tínhamos um ensino integrado, um currículo em que o aluno, ao se matricular, fazia simultaneamente a formação de $2^{\circ}$ grau, que Ihe permitiria a continuidade dos estudos e, entrelaçado com isso, uma formação técnica para uma determinada habilitação, currículo de três a quatro anos. Era um currículo rígido, no sentido de que o aluno tinha que começar e terminar aquele curso, apesar da idade difícil para o aluno estar se definindo.

Em 1997 o Ceeteps, com as mudanças realizadas, oferecia, em todas as suas escolas, três modalidades de cursos:

1. Ensino Médio/Técnico - habilitações regulares;

2. Formação Profissional Nível Técnico (Qualificação Profissional - QP III e IV);

3. Educação Profissional Nível Básico, de acordo com a nova LDB e com o decreto 2208/97.

A primeira modalidade correspondia à oferta de Ensino Médio e Ensino Técnico integrado, de acordo com a legislação anterior. A segunda destinava-se aos que haviam concluído 0 antigo ensino de $1^{\circ}$ grau ou estudos equivalentes (QP III) e aos que realizavam formação em nível de $2^{\circ}$ grau (QP IV), a qual também dava direito ao diploma de técnico, desde que o aluno tivesse concluído também $\circ 2^{\circ}$ grau regular. A terceira, finalmente, referia-se a cursos de qualificação e requalificação, realizados em convênio com a Secretaria Estadual de Relações do Trabalho, que tomaram a feição de cursos de Qualificação Profissional I (QP I), com 300 horas-aula, destinados aos que possuíam nível de escolaridade mínima, de acordo com a ocupação pretendida, ou de módulos básicos e pré-profissionalizantes ${ }^{3}$, com 100 horas-aula.

Ainda em 1997 o Ceeteps oferecia cerca de 61660 vagas, assim distribuídas: 22032 na modalidade de cursos regulares; 6863 na modalidade 
QP III e IV; 32765 na modalidade formação profissional básica. Para 1998 estavam previstas alterações de fundo na oferta de vagas nas escolas técnicas industriais, em virtude das reformulações pelas quais a instituição estava passando no sentido de adaptar-se às novas exigências legais.

De acordo com essa previsão, a oferta de vagas na modalidade Ensino Médio/Técnico cairia verticalmente de 22032 para 7223; em compensação, na modalidade Educação Profissional em Nível Técnico, o número de vagas subiria de 6863 para 20 mil; o mesmo processo ocorreria em relação à oferta de vagas para cursos de Educação Profissional Básica, que aumentaria de 32765 para 35 mil. Isso representaria uma queda de $67 \%$ na oferta de vagas para os cursos técnicos regulares, ao mesmo tempo que um aumento de aproximadamente $193 \%$ para os cursos de Qualificação Profissional III e IV e algo em torno de 7\% para os cursos de Educação Profissional Básica.

Como se pode perceber, a instituição estava em acelerado processo de adequação às novas determinações legais, no sentido de viabilizar sua vigência em relação a dois níveis da educação profissional: o técnico e o básico. A mudança prevista na oferta de vagas era, nesse caso, expressão concreta do processo de separação entre Ensino Médio e Ensino Técnico, assim como da intenção institucional de incorporar as propostas de modularização da formação técnica (via cursos de QP III e IV) para ofertá-la, concomitante ou sucessivamente ao Ensino Médio desenvolvido por ela mesma ou por escolas estaduais, municipais e particulares. Ao mesmo tempo a instituição modificava-se para ofertar cursos de curta duração, com financiamento do FAT, às parcelas menos escolarizadas ou profissionalmente menos qualificadas da população.

Para amoldar-se à nova realidade criada pela legislação federal, o Ceeteps levou em conta a Resolução no 119/97 do Conselho Estadual de Educação de São Paulo, promovendo as seguintes iniciativas e mudanças desde esse ano, ou prevendo sua efetivação nos anos seguintes:

1. Estruturação de dois tipos de cursos com base nos antigos cursos técnicos industriais: um voltado para o Ensino Médio, com matrículas em separado, funcionando no turno matutino; outro voltado para a educação profissional de nível técnico, funcionando nos turnos vespertino e noturno. O turno vespertino seria reservado ao aluno da própria escola que estivesse cursando o Ensino Médio na parte da manhã; o público-alvo do noturno seria o aluno que houvesse concluído o curso de nível médio e que trabalhasse durante o dia. A medida visava, evidentemente, evitar a ociosidade estrutural e humana da rede Ceeteps, amoldando-a à legislação federal e estadual.

2. O currículo do Ensino Médio passou a ser composto por três tipos de componentes curriculares: 
a) os que integravam a base nacional comum (núcleo comum) então em vigência, com carga horária de 2100 horas-aula de 50 minutos $^{4}$;

b) os que integravam a parte diversificada do currículo (25\% da carga horária), com 900 horas-aula de 50 minutos, subdividida essa parte em duas:

- componentes curriculares profissionalizantes de caráter geral, comuns a todas as habilitações (Ética, Gestão, Meio Ambiente, Leitura e Produção de Textos, Estatística), com carga horária de 600 horas-aula;

- componentes curriculares profissionalizantes específicos para cada área técnica, com carga horária de 300 horas-aula.

3. O Ensino Médio passou a ser organizado em ciclos com duração de dois semestres. As disciplinas da parte comum foram compactadas nos primeiros semestres e a qualificação profissional nos dois últimos semestres. $O$ ano escolar passou a ser de 40 semanas (antes era de 36). Cursados seis semestres o aluno obteria o certificado de conclusão do Ensino Médio e o certificado da Qualificação Profissional de Auxiliar, de acordo com as disciplinas específicas da parte diversificada.

4. O Ensino Técnico Industrial passou a ter currículo próprio, organizado na forma de módulos, compostos de várias disciplinas ${ }^{5}$, com carga horária mínima de 2000 horas-aula prevista na legislação (Parecer CNE $n^{\circ}$ 05/97). A previsão era a de que os cursos técnicos seriam constituídos, em sua maioria, por três módulos, com alguns cursos chegando a quatro, todos com caráter de terminalidade. À conclusão de cada módulo o aluno receberia o certificado de habilitação parcial. A conclusão dos três módulos the daria acesso ao Diploma de Técnico (habilitação plena), desde que tivesse cursado o Ensino Médio.

5. Da mesma forma que o Ensino Médio, o Ensino Técnico se organizaria com periodicidade semestral, mas, diferentemente daquele, cada semestre corresponderia a um ciclo.

A avaliação de um membro da direção do Ceeteps quanto à nova organização curricular adotada pela instituição para o Ensino Médio e para o Ensino Técnico Industrial era, em 1997, muito positiva. Segundo ele, a introdução de uma parte comum composta pelas disciplinas Ética, Gestão, Meio Ambiente, Leitura e Produção de Textos, e Estatística, na parte diversificada do Ensino Médio, significou um grande avanço. Esse diretor expressou também uma visão positiva quanto à adequação dos cursos para tornar possível sua informatização:

Também no Ensino Médio temos um projeto chamado "Encontro", que é a informatização do núcleo comum. Todos os conteúdos de todas as disciplinas já são trabalhados, já são informatizados. Há uma equipe 
de especialistas para cada disciplina, que está traduzindo, de uma maneira simples, é claro, que possibilite ao aluno e ao professor usar, ou melhor, ter aquela aula no disquete, levar para casa etc. (...) Se você pega um curso de mecânica, você já encontra mais eletrônica do que tinha há dez anos. A área de mecânica está se informatizando completamente.

Essa visão, porém, não se mostrou consensual entre os trabalhadores do Ceeteps. Um coordenador de curso de uma das escolas técnicas industriais, uma das mais tradicionais do Ceeteps, avaliou da seguinte maneira a reforma curricular e estrutural do Ensino Técnico em andamento:

O novo currículo privilegia mais a parte teórica do que a prática, mas até a quantidade da parte teórica vai ser reduzida. $O$ curso vai diminuir. Sua duração vai diminuir, e, por outro lado, eu acho que o pior de tudo, levando para o lado do social, (é que) o pessoal mais carente vai ser o mais prejudicado porque é no período noturno que se concentra o pessoal que tem maiores dificuldades financeiras. Para esse pessoal do período noturno poder ter uma qualificação como técnico, ele vai ter que ter o colegial. Para ter o colegial, ele precisa primeiro fazer três anos. Só depois ele vai poder voltar para fazer a parte técnica. A parte técnica vai acontecer depois de cursados dois semestres do Ensino Médio regular, e isso é verdadeiro para o pessoal do diurno. Quem está de manhã faz à tarde e vice-versa. O que normalmente, como já dissemos antes, pega a classe média, da média para alta. (...) O diurno agora está mais direcionado ainda para a classe média, não pode trabalhar. (...) Vem contra todo o discurso que foi feito em cima da coisa e esse pessoal (mais pobre) está simplesmente sendo deixado para trás. Ele, eventualmente, vindo à noite, trabalha durante o dia e já teria no final de três para quatro anos o curso técnico e o salário dele, pode ser no próprio emprego atual, pode dar uma melhorada, ele pode subir de posição e até conseguir bancar a sua faculdade à noite. Uma boa parte faz assim. Agora, como que ele vai fazer?

Em relação à maior integração com empresas e uma atualização para atender às demandas do mercado, outro coordenador afirmou que:

Nós temos procurado atualização, no sentido de contato com empresas, inclusive na semana da GV, que é uma atividade em que normalmente a gente convida algumas empresas para participarem, faz contatos, acaba até negociando palestras e doações (que é a 
forma que a gente tem de sobreviver em termos de material). Há alguns anos atrás, na minha área (eletrotécnica), foi feita inclusive uma pesquisa no setor de estágios, foi quando houve a reformulação da grade, não de conteúdo, onde se incluíram algumas matérias diferentes, mais atuais tipo CLP, a parte de automação, a parte um pouquinho mais aprofundada de informática etc.

Os coordenadores avaliaram também os cursos de qualificação, realizados por meio de convênio com a Sert/SP, com verbas do FAT:

A forma como os cursos da SERT estão sendo conduzidos não está agradando. Às vezes a gente nem fica sabendo (que curso será ofertado), quando fica sabendo já está na hora de dar o curso. Você vai atrás de professor, aí vem outro professor, de um outro lugar e vai dar esse curso na sua área. Adiaram várias vezes...

Como se pode notar pelo exame das inovações propostas pelo Ceeteps e, principalmente, pela sua comparação com as formulações presentes na LDB (Lei 9394/96), assim como com as determinações do Decreto 2208/97, tais inovações representaram, em 1997, mero esforço adaptativo para conformar as estruturas existentes nos Cursos Técnicos Industriais às exigências da nova legislação. O elemento relativamente novo, não previsto na legislação, ficou constituído pelos componentes curriculares da parte diversificada, comuns a todos os cursos. Esse componente curricular constituiu o espaço no qual se introduziram disciplinas que, de acordo com o discurso oficial, responderiam a algumas das demandas por qualificação de trabalhadores feitas por empresas em vias de reestruturação. Por essas razões, estendem-se a tais proposições as mesmas críticas que têm sido feitas às medidas governamentais, ressalvando-se o relativo esforço no sentido de manter, até mesmo fisicamente, alguns vínculos mais estreitos entre o Ensino Médio e o Ensino Técnico, mas ressaltando, por outro lado, que tais medidas foram tomadas em estrita observância do período de transição da antiga estrutura para aquela que deverá vigorar de forma permanente a partir de 2002.

Os três exemplos acima expressam, de diferentes formas, as mudanças que estão se operando nos antigos cursos de $2^{\circ}$ grau das redes estaduais, seja no que se refere ao Ensino Médio, seja no que diz respeito ao Ensino Técnico. Por isso foram destacados. Podem parecer, à primeira vista, exceções - e provavelmente o serão por algum tempo. Mas, ao mesmo tempo, indicam processos que estão em andamento nessas 
redes de ensino visando a um processo de adequação às novas determinações legais no campo educacional.

Em parágrafos anteriores fez-se referência ao suposto de que a reforma do Ensino Médio e do Ensino Técnico, orientadora de ações governamentais como as já descritas, decorreria de possíveis influências de organismos internacionais na sua definição. Relativamente a esse aspecto há leituras coincidentes em certos aspectos, mas discordantes em outros. Para alguns autores, as políticas educacionais recentes no Brasil seriam apenas reflexo das imposições de organismos internacionais. Cunha (1997, p. 19), reagindo a esse enfoque, afirma que:

\begin{abstract}
(...) tratando-se do Brasil, as relações entre as políticas educacionais e as recomendações (do Banco Mundial) e de outras agências internacionais só podem ser compreendidas em suas complexas mediações com protagonistas internos, individuais e institucionais, de modo que se possa pesquisar até mesmo o caminho inverso: a atuação de intelectuais orgânicos brasileiros no desenho das políticas das agências internacionais (...).
\end{abstract}

Cunha traz, em apoio à sua tese, o exemplo da participação de pesquisadores brasileiros como Cláudio de Moura Castro e João Batista de Araújo e Oliveira, ambos consultores do Banco Mundial, cujas contribuições à reforma do Ensino Médio e do Ensino Técnico não podem ser minimizadas.

Certamente, faz pouco sentido supor que organismos internacionais, por mais poderosos que sejam, tenham a condição de impor, sem colaboração interna de peso e, em muitos casos, sem orientação desses colaboradores, políticas viáveis, se não por outra razão, pelo fato de serem conhecedores dos anseios e interesses locais, mesmo que estes se refiram a grupos específicos. Coraggio (1996) concorda com a tese de Cunha, mas isso não o tem impedido de salientar a enorme influência do Banco Mundial e de outras agências internacionais na definição e na implementação das políticas educacionais na América Latina. Lauglo (1997) também faz, na condição de ex-consultor do Banco Mundial, considerações nessa direção.

Os elementos que temos coletado a respeito das políticas de formação profissional recentemente desenvolvidas no Brasil levam-nos a reconhecer, nelas, vários aspectos presentes em recomendações de organismos internacionais para essa área do ensino. Aliás, também estão presentes em algumas das proposições apontadas por Cunha. 
Esse autor faz referência a um relatório do Banco Mundial, datado de 1989 , relativo ao ensino de $2^{\circ}$ grau no Brasil. Dentre as cinco recomendações feitas ao governo brasileiro, uma tinha por objeto a iniqüidade resultante do gasto público diferenciado com as escolas de $2^{\circ}$ grau: enquanto as estaduais e municipais eram pouco aquinhoadas, as escolas técnicas federais, que atenderiam poucos alunos, de situação financeira privilegiada, recebiam altas verbas. Sem entrar na discussão das possíveis causas dessa iniqüidade, o relatório propõe:

(...) três ações imediatas voltadas para as escolas técnicas federais:

(i) a introdução do sistema de "custos compartilhados", quer dizer, a cobrança de anuidades, mediante o sistema de empréstimos do tipo crédito educativo e/ou mediante a cobrança de taxas conforme as possibilidades de cada aluno; (ii) atrair mais estudantes de baixo nível de renda para essas escolas; e (iii) expandir as matrículas mais rapidamente do que a construção de novas escolas, para reduzir o custo unitário. (Cunha 1997, p. 11)

O relatório foi objeto de análise de um grupo de técnicos brasileiros, sendo acerbamente criticado em um documento de 1991. Nele se menciona o projeto de LDB que tramitava na Câmara dos Deputados,

(...) cuja formulação estaria muito mais avançada do que a do Banco, prevendo, inclusive, o acesso de todos à escola básica, associando a educação geral e a educação tecnológica. Contrariamente a isso, o Banco insistia na substituição do Ensino Técnico pela educação geral, seguida da educação profissional mais rápida. (Cunha 1997, p. 12; grifos nossos)

Não obstante essa reação, Cunha destaca que na proposta de governo de Fernando Henrique Cardoso, por ocasião das eleições, a tese do Banco Mundial que investe contra as escolas técnicas é retomada:

numa referência implícita ao relatório (...) para o ensino secundário brasileiro, a proposta diz que cabe fazer um remanejamento das verbas do ministério para o ensino de $2^{\circ}$ grau, realocando ou criando fontes adicionais de recursos, ao invés de ampliar a rede de escolas técnicas federais, que só atenderiam uma minoria insignificante da população escolar. (Cunha 1997, p. 13, grifos do autor) 
Como verificaram mais tarde o próprio Cunha e outros pesquisadores brasileiros que vêm acompanhando as reformas do Ensino Médio e do Ensino Técnico (especialmente este), o que era proposta de campanha transformou-se em justificativa das reformas. Em perfeita consonância com as proposições do Banco Mundial (apesar de criticadas em 1991) e, pelo menos em parte, com as de seus consultores (Cláudio de Moura Castro e João Batista de Araújo e Oliveira), a reforma é justificada pelos altos custos das escolas técnicas e pelo "desvio de função": seus egressos, em vez de se dirigirem ao mercado de trabalho imediatamente, como seria "natural", teimam em disputar vagas nos cursos superiores (onde ingressam em grande número). ${ }^{6}$ Como se pode notar, o Banco Mundial, diretamente ou por interpostos consultores, desempenhou, sim, papel importante na definição dos rumos da reforma.

Nesse particular, o açodado processo de adaptação às recomendações internacionais, os casos do Paraná e de Minas são emblemáticos. Mesmo antes da aprovação da LDB e do Decreto 2208/97, tais estados já haviam se posto a campo para indicar, na prática, os rumos a seguir, quer em relação ao Ensino Médio, quer no que diz respeito ao Ensino Técnico. Minas Gerais, além disso, adotou um procedimento passível de crítica também pela forma de indicar as mudanças que a SEE considerava desejáveis. Baseando-se, sem crítica, no princípio simplista de que o ensino (não apenas técnico) deve organizar-se tomando por parâmetro as supostas necessidades da economia e de que, em o fazendo, contribui, de um lado, para a inserção vantajosa do estado e do país no mercado internacional e, de outro, para aumentar a "empregabilidade" dos egressos, operou um paralelismo mecânico entre cursos existentes e as presumíveis necessidades da economia para recomendar adequações destes, ou de cursos potenciais, a tais necessidades, sem estudos mais aprofundados do mercado de trabalho, apoiando-se em suposições muito questionáveis da perspectiva desse mesmo mercado, especialmente nas condições criadas pela produção e pelos serviços de caráter capital intensivo (por exemplo, a de que ele se pauta pelo estoque de trabalhadores qualificados, ou a de que a freqüência aos cursos amplia as possibilidades de inserção ou, ainda, a de que os mercados são estanques).

Por outro lado, as três ações descritas remetem a reflexões sobre as finalidades da educação básica brasileira. No que se refere à educação profissional é certamente compreensível que esta se volte para as necessidades de diferentes setores da economia, posto que a ela cabe, especificamente, capacitar trabalhadores para esses setores. No entanto, o que parece ocorrer é a extensão indevida desse tipo de finalidade para o Ensino Médio em 
geral. Cunha (1997, p. 17) chama a atenção para o fato de que a LDB recentemente aprovada "traz uma concepção claramente profissionalizante do Ensino Médio" (não no sentido atribuído a esse termo na Lei 5692/71), expressa principalmente no inciso II do artigo 35 , em que o preparo para o trabaIho e para a adaptação flexível às futuras condições profissionais têm precedência em relação à formação para a cidadania. Esse mesmo autor pontua o destaque dado na LDB ao "domínio dos princípios científicos e tecnológicos que presidem a produção moderna", quer no referente às finalidades do Ensino Médio, quer no que diz respeito ao currículo e à avaliação.

Esse tipo de proposição contida na LDB sugere uma clara adesão aos novos enfoques produtivos (por meio, por exemplo, do inciso II acima referido) e, ao mesmo tempo, uma suposta adesão às teses da educação tecnológica de inspiração marxiana (por intermédio, por exemplo, do inciso IV do mesmo artigo 35). Como o procedimento de referir-se aos interesses capitalistas pela utilização de referenciais construídos por enfoques teóricos que a eles se opõem tem se tornado, ultimamente, uma prática comum entre empresários e seus prepostos (acadêmicos ou parlamentares), convém ler com muita cautela algumas proposições "generosas" contidas na LDB.

Por essa razão é justificável a apreensão de Cunha. Ela nos alerta para a necessidade de acompanhar, com atenção, a possível investida dos interesses produtivos sobre o Ensino Médio, colocando não apenas a educação profissional, mas todo o ensino de $2^{\circ}$ grau a seu serviço, justificando tal procedimento com as novas demandas por qualificação de caráter geral que a flexibilização produtiva faz aos trabalhadores. Isso não é mera elucubração teórica. Ao se referir às sugestões e recomendações de Cláudio Moura Castro e João Batista Araújo e Oliveira para o Banco Mundial, no que diz respeito ao ensino de $2^{\circ}$ grau, Cunha traz à tona a convergência de opiniões entre ambos quanto aos conteúdos a serem privilegiados pelo Ensino Médio:

Mas a solução que Castro defende como a mais apropriada é a que estaria sendo aceita na Europa: rejeitar o ensino de $2^{\circ}$ grau meramente propedêutico tanto quanto a "velha opção profissionalizante" em proveito de cursos secundários aplicados ou mais voltados para certas áreas, como as comerciais, as artísticas, as biológicas, as industriais. A idéia não seria a de profissionalizar, mas, sim, "vestir" os mesmos conteúdos acadêmicos (ciências, matemática, comunicação, escrita) com "roupagens" da área. E exemplifica: aprende-se matemática aplicada nos negócios; física, estudando máquinas-ferramenta; ler e escrever, redigindo relatórios e lendo manuais de computador (...). 
(...) Oliveira (defende a solução dos) sistemas educacionais da OCDE, em reforma, (que propõe) a adoção dos cursos que procuram ensinar disciplinas acadêmicas num contexto aplicado, ao mesmo tempo em que permitem ao aluno aprofundar, desde cedo, seus conhecimentos e habilidades nas áreas em que possui maior vocação ou talento, assim como habituar-se às características e demandas do mundo do trabalho. Ao invés de prepararem para ocupações específicas, esses cursos tipo tech prep norte-americano visam a áreas educacionais cada vez mais amplas, embora "vocacionadas e direcionadas", o que permitiria aos alunos o desenvolvimento intelectual, o domínio da competência e a busca da excelência. (Cunha 1997, pp. 13 e 15)

A rapidez com que estão ocorrendo os processos de adaptação dos sistemas escolares às proposições de reforma é, ao mesmo tempo, familiar e preocupante. Familiar porque não é a primeira vez que se assiste, no campo educacional, a tal tipo de movimento, muito ao feitio do que Cunha denomina de "administração ziguezague", caracterizada pelo "fato de que cada ministro ou secretário de educação tenha a sua idéia 'salvadora' para a crise da educação, o seu plano de carreira, a sua proposta curricular, o seu tipo de arquitetura escolar, as suas prioridades". Cunha é particularmente ácido em relação a essa característica da reforma. Apesar de longa, a citação abaixo é muito ilustrativa de seu ponto de vista:

O Ensino Técnico foi objeto de mais um movimento do tipo ziguezague que tanto tem contribuído para a desorganização, a piora de qualidade e a desmotivação dos docentes no Brasil. No caso em foco, o ziguezague provém de um claro experimentalismo pedagógico, qual seja, a tentativa de fazer do Ensino Médio um tal de tech prep ${ }^{7}$, ensaiado em alguns estados americanos. Não deixa de estar presente, também, o voluntarismo ideológico, não o de inspiração socialista que eu havia identificado em Educação, Estado e Democracia no Brasil, mas, sim, uma inspiração reacionária, aquela que procura discriminar os alunos que têm o destino de ascensão educacional e social dos que devem se resignar a permanecer na posição que Deus Ihes deu ou, então, mobilizar um especial talento para dele escapar. É a celebração da eqüidade, ao invés da igualdade. O ziguezague é particularmente danoso por representar uma volta atrás no processo de unificação da estrutura educacional que, anunciado pelo Manifesto dos Pioneiros da Educação Nova, de 1932, vinha se desenvolvendo desde a promulgação das "leis de equivalência" dos anos 50 . A volta atrás que agora se dá, ao contrário de um avanço da articulação entre educação 
e democracia, deverá representar o reforço da dualidade escolar, contribuindo para a estamentização das situações de classe.

Fato semelhante ocorreu com a implantação dos cursos profissionalizantes compulsórios logo após o advento da Lei 5692/71, os quais, além de não promover (porque na verdade não poderiam) a integração teoria/prática, conseguiram piorar o Ensino Médio então existente. E, retomando, preocupante porque, de um lado, tais processos de adaptação podem gerar problema semelhante em relação aos cursos técnicos, principalmente os federais, que conseguiram, apesar do que vem acontecendo com o ensino público brasileiro, manter um relativo nível de qualidade e, de outro, porque revelam o açodamento do governo federal e também de governos estaduais na implantação de reformas muito pouco debatidas.

\section{Notas}

1. Federação da Indústria do Estado de Minas Gerais. Gerência de Relações Internacionais e Comércio Exterior/ Gerência de Assuntos Econômicos (Minas em Síntese, fev. 1996).

2. Os Pólos Regionais são formados por Superintendências Regionais de Ensino (SREs). Os pólos e suas respectivas SRES são: Pólo Metropolitano: Belo Horizonte, Conselheiro Lafaiete, Divinópolis, Ouro Preto, Sete Lagoas; Pólo Norte: Curvelo, Diamantina, Januária, Montes Claros, Pirapora; Pólo Vale do Aço: Almenara, Caratinga, Coronel Fabriciano, Governador Valadares, Guanhães, Manhaçu, Nova Era, Teófilo Otoni; Pólo Mata: Barbacena, Carangola, Juiz de Fora, Muriaé, Ponte Nova, São João Del Rei, Ubá, Leopoldina; Pólo Sul: Campo Belo, Caxambu, Itajubá, Passos, Poços de Caldas, Pouso Alegre, São Sebastião do Paraíso, Varginha.

3. O significado da expressão não foi esclarecido.

4. Em entrevista, um dos diretores deixou claro que a manutenção do núcleo comum do antigo ensino de $2 \underline{o}$ grau se devia ao fato de, na época, não terem sido ainda definidos os parâmetros curriculares correspondentes ao Ensino Médio, o que não impediu a instituição de, em publicação a respeito das inovações a serem introduzidas, afirmar que se pretendia que o aluno dominasse, ao final desse núcleo comum, os conhecimentos referidos às três grandes áreas descortinadas para a definição desses parâmetros.

5. Um diretor entrevistado mostrou-se recalcitrante quanto à adoção dos módulos. Embora visse a iniciativa com bons olhos, especialmente no que se refere à certificação do aluno após cada módulo, também manifestou apreensão, "porque existem poucas experiências e poucos estudos". 
6. A respeito desses dois aspectos cabem algumas considerações. Relativamente aos custos do ensino oferecido pelas escolas técnicas federais, Cunha (1997) relata que, ao procurar informações mais recentes sobre o assunto, verificou, com surpresa, que os únicos dados de pesquisa a esse respeito eram os veiculados por seu estudo de 1973 sobre o Ensino Técnico no Brasil, com base em pesquisa de Corrêa da Costa de 1968. Relativamente ao caráter elitista das escolas técnicas federais, deve-se perguntar qual será o provável perfil dos alunos a serem atendidos após a reforma, considerando que, na hipótese da concomitância, os interessados em obter o diploma de técnico teriam que, durante quatro anos, freqüentar simultaneamente, portanto em tempo integral, cursos médios de formação geral e cursos técnicos, e na hipótese da formação técnica sucessiva, acrescentar pelo menos mais dois anos aos três anos do curso de nível médio.

7. Cunha está se referindo aqui aos chamados currículos "acadêmicos" aplicados, utilizados nas reformas dos sistemas educacionais de países da OCDE e em experimentação nos Estados Unidos, cuja adoção, no Brasil, foi proposta por João Batista de Araújo e Oliveira, consultor do Banco Mundial.

Recebido para publicação em março de 2000

\section{Changes in the state teaching system facing the reforms in high school and technical teaching}

ABSTRACT: This is an analysis of the new government proposal for high school learning structure for the professional education, focusing the differences between technique and technological instruction as a scope of official speech and the practical introduction of a proposal. Using empirical data from technical schools after such changes, the text discuss the properties of school practices to technological teaching, showing the lost of identity of this kind of school to give an answer to a technological teaching engaged with social education

\section{Referências Bibliográficas}

CORAGGIO, J.L. "Propostas do Banco Mundial para a educação: Sentido oculto ou problemas de concepção?". In: DE TOMMASI, L.; WARDE, M.J. e HADDAD, S. (orgs.). O Banco Mundial e as políticas educacionais. São Paulo: Cortez/PUC-SP/Ação Educativa, 1996.

CUNHA, L.A. "Ensino Médio e ensino profissional: Da fusão à exclusão". 1997. Mimeo. 
FERRETTI, C.J. "Formação profissional e reforma do Ensino Técnico no Brasil: Anos 90". Educação \& Sociedade nº 59. Campinas: Cedes, ano XVIII, ago. 1997.

LAUGLO, J. "Crítica às prioridades e estratégias do Banco Mundial para a educação". Cadernos de Pesquisa no 100. São Paulo: Cortez, mar. 1997.

MINAS GERAIS/SEE. "Distribuição dos cursos profissionalizantes dos sistemas de ensino federal, estadual, municipal e particular nas Superintendências Regionais de Ensino e nos Pólos Regionais de Minas Gerais". 1996. Mimeo.

. "Estimativas da população em idade escolar do Estado de Minas Gerais. Superintendências Regionais de Ensino e respectivos municípios - período 1991-2006". 1996. Mimeo.

"Análise da adequação entre as características econômicas das Superintendências Regionais de Ensino e a oferta de cursos de $2^{\circ}$ grau, acadêmico e profissionalizante, em Minas Gerais". 1996. Mimeo.

PARANÁ/SEED. Programa Expansão, Melhoria e Inovação no Ensino Médio do Paraná. Governo do Estado, 1995. 